\title{
The Characteristics of Patients who have Undergone Total Vaginal Hysterectomy Procedure at Dr. Sardjito Hospital Yogyakarta
}

\author{
Hervianto Mukti Utomo ${ }^{1}$ and Nuring Pangastuti ${ }^{2 *}$ \\ ${ }^{1}$ Obstetrics and Gynaecology Specialist Education Program, Department of Obstetrics and Gynaecology, Faculty of Medicine, \\ Public Health and Nursing, Universitas Gadjah Mada, Yogyakarta, Indonesia
}

${ }^{2}$ Obstetrics and Gynaecology Department, Faculty of Medicine, Public Health and Nursing, Universitas Gadjah Mada, Yogyakarta, Indonesia

*Corresponding author: Nuring Pangastuti, Obstetrics and Gynaecology Department, Faculty of Medicine, Public Health and

Nursing, Universitas Gadjah Mada, Yogyakarta, Indonesia

\section{ARTICLE INFO}

Received: 慧 August 01, 2021

Published: 蔧 August 20, 2021

Citation: Hervianto Mukti Utomo, Nuring Pangastuti. The Characteristics of Patients who have Undergone Total Vaginal Hysterectomy Procedure at Dr. Sardjito Hospital Yogyakarta. Biomed J Sci \& Tech Res 38(2)-2021. BJSTR. MS.ID.006132.

Keywords: Hysterectomy; Total Vaginal Hysterectomy (TVH); Age; Parity; Uterine Prolapse

\section{ABSTRACT}

Introduction: Total Vaginal Hysterectomy (TVH) procedure are recently used as one of surgical procedure in gynecology field to totally remove the uterus. This procedure were recommended by American College of Obstetricians and Gynecologists to minimize surgical injury, reduce blood loss and costs of the surgery.

Objective: This study aims to determine description of the patients's characteristics who have undergone the Total Vaginal Hysterectomy (TVH) procedure at Dr Sardjito Hospital, Yogyakarta, Indonesia.

Methods: This research is a descriptive analysis using secondary data obtained from medical records. Three characteristics were taken namely age, parity, and diagnosis.

Results: Within 11 months (November 2018 - September 2019), there were 21 patients that have carried out TVH procedures. There were 2 patients at the age below 65 years old, nineteen patients were 65 years old or older. Based on the parity, there was 1 nulliparous patient, 14 multiparous, and 6 grandemultipara patients. There was no primiparous patient. According to the diagnosis, there was 1 patient with grade 1-2 uterine prolapse, 20 patients with grade 3-4 uterine prolapse. Accompanying diagnosis in patients performed this procedure was 1 patient with grade $1-2$ of cystocele, 20 patients with grade 3-4 of cystocele, 3 patients with grade 1-2 of rectocele, and 18 patients with grade 3-4 of rectocele.

Conclusion: The characteristics of patients who have undergone TVH procedures at Dr Sardjito Hospital Yogyakarta almost all of them were the same age as or more than 65 years old, multiparous, and with the underlying diagnosis was grade 3-4 of uterine prolapse.

\section{Introduction}

Total Vaginal Hysterectomy (TVH) procedure are recently used as one of surgical procedure in gynecology field to totally remove the uterus. Compared to Total Abdominal Hysterectomy (TAH), TVH is more further reduce the risk of genitourinary tract trauma. TVH procedures is recommended by American College of Obstetricians and Gynecologists to minimize surgical injury, reduce blood loss 
and costs of the surgery. At Dr Sardjito Hospital, TVH procedures have been carried out as a procedure for uterine prolapse surgery. An evaluation of the patient's background characteristics and a diagnosis that underlies the selection of TVH procedures for these cases is needed.

\section{Subjects and Methods}

The subjects in this study were patients who have undergone the TVH procedure within 11 months (November 2018 - September 2019). This research is a descriptive analysis using secondary data obtained from medical records at Dr Sardjito Hospital, Yogyakarta, Indonesia. Three characteristics were taken namely age, parity, and diagnosis.

\section{Results}

The characteristics of patients who have undergone TVH procedures at Dr Sardjito Hospital Yogyakarta mostly were the same age as or more than 65 years old, multiparous, and with the underlying diagnosis was grade 3-4 of uterine prolapse.

\section{Discussion}

According to the secondary data analysis performed on patients undergoing the TVH procedure within 11 months (November 2018 - September 2019) it was found that there were 21 patients who have undergone the TVH procedure. In Ercan, et al. [1], it is stated that TVH procedures is recommended by American College of Obstetricians and Gynecologists to minimize surgical injury, blood loss, and cost. The following are the results obtained through the secondary data analysis based on medical records at Dr. Sardjito Hospital (Table 1). There were 2 patients at the age below 65 years old (9.5\%), nineteen patients were 65 years old or older $(90.5 \%)$. Based on the parity, there was 1 nulliparous patient (4.7\%), 14 multiparous (66.67\%), and 6 grandemultipara patients $(28.6 \%)$. There was no primiparous patient [2]. According to the diagnosis, there was 1 patient (5\%) with grade 1-2 uterine prolapse, 20 patients (95\%) with grade 3-4 uterine prolapse. Accompanying diagnosis in patients who have undergone this procedure was 1 patient (5\%) with grade $1-2$ of cystocele, 20 patients (95\%) with grade 3-4 of cystocele, 3 patients $(14.3 \%)$ with grade $1-2$ of rectocele, and 18 patients (85.7\%) with grade 3-4 of rectocele [3]. In other words, the characteristics of patients who have undergone TVH procedures at Dr Sardjito Hospital Yogyakarta mostly were the same age as or more than 65 years old, multiparous, and with the underlying diagnosis was grade 3-4 of uterine prolapse.

Table 1: The Result of the Characteristics of Patients who Have undergone TVH Procedure November 2018 - September 2019.

\begin{tabular}{|c|c|c|c|c|}
\hline \multicolumn{5}{|c|}{ Characteristics } \\
\hline \multirow{3}{*}{ Age } & & & Number of Patients & Percentage \\
\hline & \multicolumn{2}{|c|}{$<65$} & 2 & $9,5 \%$ \\
\hline & \multicolumn{2}{|c|}{$\geq 65$} & 19 & $90,5 \%$ \\
\hline \multirow{4}{*}{ Parity } & \multicolumn{2}{|c|}{ NULLIPAROUS } & 1 & $4,7 \%$ \\
\hline & \multicolumn{2}{|c|}{ PRIMIPAROUS } & - & - \\
\hline & \multicolumn{2}{|c|}{ MULTIPAROUS } & 14 & $66,67 \%$ \\
\hline & \multicolumn{2}{|c|}{ GRANDEMULTIPARA } & 6 & $28,6 \%$ \\
\hline \multirow{6}{*}{ Diagnosis } & \multirow{2}{*}{ UTERINE PROLAPSE } & Grade 1-2 & 1 & $5 \%$ \\
\hline & & Grade 3-4 & 20 & $95 \%$ \\
\hline & \multirow{2}{*}{ CYSTOCELE } & Grade 1-2 & 1 & $5 \%$ \\
\hline & & Grade 3-4 & 20 & $95 \%$ \\
\hline & \multirow{2}{*}{ RECTOCELE } & Grade 1-2 & 3 & $14,3 \%$ \\
\hline & & Grade 3-4 & 18 & $85,7 \%$ \\
\hline
\end{tabular}

\section{Conclusion}

The characteristics of patients who have undergone TVH procedures at Dr Sardjito Hospital Yogyakarta almost all of them were the same age as or more than 65 years old, multiparous, and with the underlying diagnosis was grade 3-4 of uterine prolapse.

\section{Acknowledgement}

Paper presented at the 2020 Indonesian Uroginecological Association Annual Scientific Meeting in a poster presentation.

\section{References}

1. Ercan Ö, Özer A, Köstü B, Bakacak M, Kıran G, et al. (2016) Comparison of postoperative vaginal length and sexual function after abdominal, vaginal, and laparoscopic hysterectomy. International journal of gynaecology and obstetrics: the official organ of the International Federation of Gynaecology and Obstetrics 132(1): 39-41.

2. Veronikis DK (2015) Vaginal Hysterectomy: The Present Past. Missouri medicine 112(6): 439-442.

3. Mamik MM, Antosh D, White DE, Myers EM, Abernethy M, et al. (2014) Risk factors for lower urinary tract injury at the time of hysterectomy for benign reasons. Int Urogynecol J 25(8): 1031-1036. 
ISSN: 2574-1241

DOI: 10.26717/BJSTR.2021.38.006132

Nuring Pangastuti. Biomed J Sci \& Tech Res

(c) (P) This work is licensed under Creative BY Commons Attribution 4.0 License

Submission Link: https://biomedres.us/submit-manuscript.php

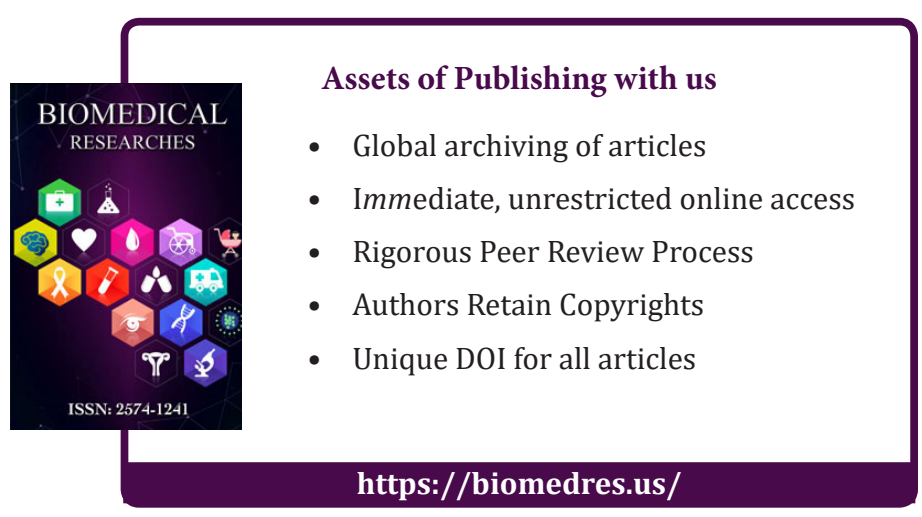

